\title{
COMENTÁRIO
}

\section{O REALISMO EPISTÊMICO EM IMRE LAKATOS}

\author{
Marcos Rodrigues da Silva ${ }^{1}$
}

Referência do texto comentado: BORGE, Bruno. ¿̨Fue lakatos un realista epistémico?: el rol de la verdad en la metodología de los programas de investigación científica. Trans/Form/Açáo: revista de filosofia da Unesp, vol. 43, Número Especial, p. 47-72, 2020.

Uma das críticas mais frequentes àquilo que se costuma denominar "abordagem historiográfica”, em filosofia da ciência, é a de que essa abordagem seria um obstáculo à noção de verdade em ciência. Expressando isso em termos filosóficos ligeiramente mais técnicos: a abordagem historiográfica, por empregar categorias mais amplas que a categoria "teoria" (paradigmas, programas de pesquisa, tradiçóes de investigaçáo), descuidaria da dimensão epistemológica presente nas ciências naturais. Paradigmas, programas de pesquisa, tradiçóes de investigação, reivindicam seus proponentes, não são verdadeiros ou falsos - ao invés, são eficientes, progressivos, diretivos, programáticos etc.

Uma das categorias acima mencionadas é exatamente a de programas de pesquisa, de Imre Lakatos, objeto de investigação do artigo " ¿Fue Lakatos un Realista Epistémico? El Rol de la Verdad en la Metodología de los Programas de Investigación Científica”, do filósofo Bruno Borge. O argumento central de Borge é de que Lakatos náo deixa de lado questóes epistêmicas, devendo

${ }^{1}$ Docente do Departamento de Filosofia da Universidade Estadual de Londrina, Londrina, Paraná Brasil. (D) https://orcid.org/0000-0003-3388-6381 E-mail: mrs.marcos@uel.br

http://doi.org/10.1590/0101-3173.2020.v43esp.05.p73

\section{(1)}


inclusive ser considerado um realista epistêmico; ou seja, sua concepção de programas de pesquisa seria condutora de verdade, e as teorias componentes de um programa de pesquisa poderiam ser consideradas verdadeiras.

Antes de mais nada, é importante situar os referenciais lakatosianos, bem como pesar a importância de tais referenciais. Lakatos estava, é claro, atento à alternativa apresentada por Thomas Kuhn de que uma análise da ciência deveria ser feita levando-se em consideração não apenas teorias específicas, mas orientaçóes gerais - chamadas por Kuhn de paradigmas. Mesmo assim, é inegável que o interlocutor direto da argumentaçáo de Lakatos era a concepção falseacionista de Karl Popper. Talvez não seja exagero afirmar que Lakatos estivesse desejando preservar o falseacionismo popperiano, no interior de uma unidade maior que uma teoria - isto é, no interior de um programa de pesquisa. Assim, desde o início, o diagnóstico proposto por Bruno Borge parece totalmente correto: como, para Popper, o interesse estava localizado no aumento de conteúdo de empírico de uma teoria (e, nesse sentido, o falseacionismo era um componente essencial desse interesse), Lakatos estaria trilhando exatamente o mesmo caminho, alterando apenas a unidade desse aumento de conteúdo empírico: as teorias aumentariam seu conteúdo empírico, mas esse acréscimo seria a contribuição dessas teorias para os programas de pesquisa nos quais estariam inseridas.

Borge (2020, p.59), também corretamente, alerta para a preocupação de Lakatos em estabelecer "[...] criterios precisos acerca de las condiciones que un programa de investigación científica ha de reunir para ser considerado progresivo [...]". Como se sabe, Lakatos divide um programa de pesquisa em duas partes: i) um núcleo - considerado por convenção irrefutável; ii) um cinturão protetor: constituído por teorias que têm o objetivo de fortalecer o núcleo. A progressividade provém exatamente da atuação bem-sucedida das teorias específicas que fortalecerão o núcleo. Ora, essas teorias são refutáveis, se relacionam com a realidade, são verdadeiras ou falsas. Assim, como bem argumenta Borge, os critérios são bastante precisos.

A dificuldade que pode aparecer em um esquema desse tipo é a de que, assumindo-se a mediação dos programas de pesquisa, os enunciados das teorias que compóem o cinturão protetor, por estarem relacionados a enunciados irrefutáveis (por convenção), não teriam relação com a realidade. Porém, Borge (2020, p. 63) trata essa dificuldade de modo coerente com a metodología de Lakatos: 
Lakatos no supone que sea el mundo mismo [...] el que justifica la determinación del valor de verdad de un enunciado. Por el contrario, son sus relaciones con otros enunciados los que posibilitan su verificación, sin embargo, eso no significa que si alcanzásemos un conocimiento objetivo acerca del mundo, ese conocimiento fuese acerca de otros enunciados.

Nesse sentido, a apreciação de Borge acerca de Lakatos como um realista epistêmico não desloca Lakatos do realismo epistêmico defendido por autores mais atuais, como Peter Lipton e Stathis Psillos.

Um outro ponto de destaque do artigo de Borge é a defesa da abordagem historiográfica de Lakatos, especificamente seu recurso à história da ciência. Borge alude a uma crítica de Papineau, o qual acredita que a utilização da história da ciência implica uma circularidade, uma vez que se assumiria o êxito científico para explicar o próprio êxito científico. Nesse ponto do artigo, entendo, Borge procura defender Lakatos argumentando que seu recurso à história da ciência não significa o abandono da noçáo de verdade e, portanto, Lakatos permaneceria um realista epistêmico coerente.

Além disso, o que me parece mais pertinente, no artigo de Borge, é sua ênfase em uma questão que é tanto conceitual quanto histórica. Uma evidência contrária, em termos popperianos, significava uma refutaçáo. Para Lakatos, como lembra Borge, uma evidência contrária é uma oportunidade para uma revisão conceitual e, com isso, uma possibilidade de progresso de um programa de pesquisa:

Las refutaciones, es decir, la indicación de cierto contenido falso en nuestros programas, introducen inconsistencias en nuestro sistema de conocimiento. En una nota a pie de página Lakatos insiste en el hecho de que ese fenómeno no marca la refutación de una teoría en particular sino la necesidad de resolver la inconsistencia de manera progresiva. (BORGE, 2020, p. 65-66)

Não restam dúvidas de que a história da ciência funciona, em boa parte, dessa maneira. (Nesse sentido, inclusive, abre-se uma interesante porta de diálogo entre a posição de Lakatos e a posterior declaração de Larry Laudan, de que o progresso da ciência, de modo geral, ocorre por meio de soluçóes de problemas e anomalias.) 
Finalizando, o artigo de Bruno Borge é uma importante contribuição para o debate acerca da importância de se relacionar o registro histórico da ciência com a dimensão epistemológica da ciência, e também com o realismo científico.

\section{Referência}

BORGE, Bruno. ¿Fue lakatos un realista epistémico?: el rol de la verdad en la metodología de los programas de investigación científica. Trans/Form/Ação: revista de filosofia da Unesp, vol. 43, Número Especial, p. 47-72, 2020. 